\title{
Gastrocolocutaneous Fistula Following Percutaneous Endoscopic Gastrostomy in an Octogenerian Patient
}

\author{
Sevda Yılmaz, Muhammed Raşid Aykota and Ali Kağan Gökakın* \\ Department of General Surgery, Turkey \\ *Corresponding author: Ali Kağan Gökakın, Department of General Surgery, Turkey
}

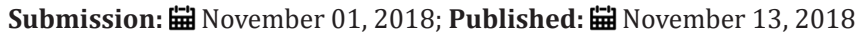

\section{Introduction}

Percutaneous endoscopic gastrostomy (PEG) is a safe and simple technique for the provision of enteral nutrition with extremely low complication rates [1]. It was first described by Gauderer and Ponsky in 1979 and then came popular in time [2]. Although most complications are minor, such as peristomal skin infections, tube dislocation, or leakage, occasionally severe complications can be seen such as internal organ damage, necrotising fasciitis, or aspiration pneumonia $[3,4]$. The extremely rare complication of gastrocolocutaneous fistula developing because of perforation of the colon by the PEG catheter during placement or erosion of adjacent intestines when inside, can be seen at the rate of $0.5 \%$ $3 \%[5,6]$. The case is here presented of a patient who developed gastrocolocutaneous fistula fallowing PEG placement.

\section{Case Report}

Following respiratory failure developing because of cerebrovascular disease, an 82-year old male patient was attached to a respiratory device for 2 months in the Anaesthesia Intensive Care Unit (ICU) of Pamukkale University Medical Faculty Hospital. Due to the development of abdominal swelling and the inability to pass gas or stools, General Surgery consultation was requested. In the evaluation of the patient, it was seen that he had been receiving Alzheimer's disease treatment for 2 years in addition to treatment for diabetes mellitus and hypertension. The PEG tube had been applied in the anaesthesia ICU 10 days previously for nutritional purposes. In the physical examination of the patient, there was distension and sensitivity of the abdomen. When the laboratory test results of the patient were examined, leukocytosis was seen to have developed (WBC:7.40k/Ul) and other values were as follows: a slight shift to the left in the neutrophil value (NEU:76.4\%), Hemoglobin 8.2g/Dl, Hematocrit 26.4\%, CRP 10.378mg/Dl, Glucose 188 mg/Dl, Total Protein 5.67g/Dl, Albumin 23.6g/ $\mathrm{Dl}$, and other laboratory parameters were normal. Abdominal tomography of the patient was taken with the application of oral non-ionic contrast and there was observed to be widespread intraabdominal air, and the PEG catheter was seen to have extended to the stomach by traversing the transverse colon. There was not seen to be any significant extralumination of the oral contrast substance. Distension and loss of haustration were seen to extend to $7.5 \mathrm{~cm}$ of the sigmoid colon. An emergency laparotomy operation was performed. During the surgery, the transverse colon, stomach and loops of the small intestine were observed to have become entwined. After eliminating the adhesions, it was seen that the PEG catheter had reached the stomach by passing all layers of the transverse colon (Figure 1,2). The PEG catheter was removed with a wedge resection of the stomach, a transverse loop colostomy was opened from the entry site of the catheter to the transverse colon, and tube jejunostomy was applied for nutrition. The patient was intubated and followed up postoperatively in the anaesthesia ICU. On postoperative day 1 after the jejunostomy, enteral nutrition was started, and with continuing toleration of the enteral nutrition and functioning of the colostomy, the patient was transferred from ICU follow-up to the Anaesthesia department with no complications. At 2 months postoperatively, the patient died from cardiac arrest.



Figure 1: PEG catheter had reached the stomach by passing all layers of the transverse colon. 


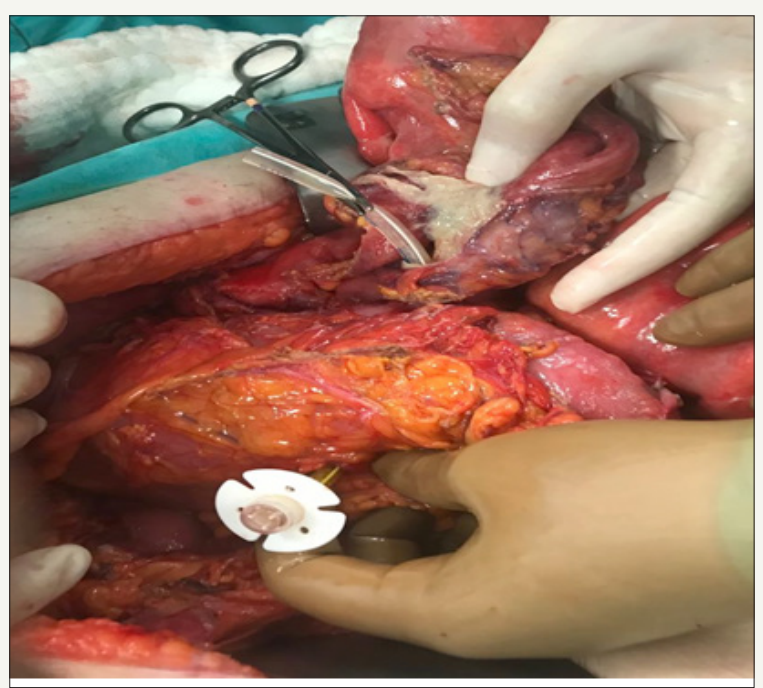

Figure 2: PEG catheter had reached the stomach by passing all layers of the transverse colon.

\section{Discussion}

PEG is a safe and effective method to continue enteral nutrition in patients with normal gastrointestinal functions but for various reasons cannot take nutrition orally. Since it was first described in 1979 it has become widely used in place of open gastrostomy [2]. Just as in the current case, the majority of patients applied with PEG have cerebrovascular diseases $[7,8]$. PEG is a less invasive method, which does not require general anaesthesia and is applied with more than $95 \%$ success [9]. However, complications related to PEG tube have been reported in literature at rates varying from $6 \%$ to $17 \%$ [110]. Gastrocolocutaneous fistula related specifically to PEG tube is a rare complication seen at the rate of approximately $0.5 \%-3 \%$ [6]. Factors contributing to the development of gastrocolocutaneous fistula have been determined as a high transverse colon, abnormal posture, spinal deformity and excessive stomach dilatation during gastroscopy [5-12]. The current case was diabetic and had been intubated and bedridden in ICU for 2 months and was therefore at high risk of gastric stasis (Figure 3).



Figure 3: Preoperatively 3D computed scan image.
Although previous abdominal surgeries are accepted as a significant risk factor for gastrocolocutaneous fistula, in a study of 28 cases of gastrocolocutaneous fistula, only 8 had a history of previous abdominal surgery [11-13]. Similarly, there was no history of abdominal surgery in the currrent case. Although the mechanisms of the development of gastrocolocutaneous fistula are not fully known, there are some theories that seem to be more probable. Gastrocolocutaneous fistula can develop as direct perforation of the colon by the PEG catheter as a result of interpositioning between the abdominal wall of the colon and the stomach during PEG application or as erosion of the adjacent intestine over time because of over-stretching of a previously placed PEG tube [5-9]. Although the development of fistula is often during placement of the PEG tube, there is generally an asymptomatic period between the application of PEG and the emergence of symptoms [14]. And in literature, asymptomatic periods of up to as long as 9 months have been reported [5]. In the current case, there was seen to be a similar asymptomatic period of approximately 10 days.

Diarrhea is seen as a typical symptom because of the leakage of gastric contents to the colon via the fistula [5]. The symptom of diarrhea with food content which occurs after the symptomatic period should be a warning in respect of gastrocolocutaneous fistula in patients with PEG. The onset of diarrhea and abdominal pain in the form of cramp immediately after tube feeding, the odour of faces from the stoma and fecaloid vomiting are other symtoms which may be seen [5-15]. In contrast to the information in literature, there was no complaint of diarrhea in the current case, but there was obstruction. Upper gastrointestinal system endoscopy is recommended for cases with suspected gastrocolocutaneous fistula. Diagnosis is made from direct radiographs applied with watersoluble contrast dye or abdominal computed tomography (CT) [16]. As the current case presented with mechanical obstruction, abdominal CT using orally-administered water-soluble contrast substance was preferred.

There is no standard treatment approach for gastrocolocutaneous fistula recommended in literature. 
However, in cases with peritoid findings, emergent laparotomy is recommended, while in most cases that do not require surgery, primary treatment is recommended of a wide spectrum of endoscopic methods from spontaneous or endoscopic hemoclip to cardiac septal defect closure devices [14-20]. As the current case had peritonitis, emergency laparotomy was applied. In conclusion, because of increasing life expectancy and the associated increase in cerebrovascular diseases, there is an increased need for PEG and therefore an increase has been seen in PEG-related complications. The development of gastrocolocutaneous fistula associated with PEG is a rare but fatal complication. Care must be taken in patients at risk of the development of gastrocolocutaneous fistula and early diagnosis is of great importance.

\section{References}

1. Strodel WE, Ponsky JL (1988) Complications of percutaneous gastrostomy. In: Ponsky JL (Ed.), Techniques of Percutaneous Gastrostomy. Igaku-Shisein, New York, USA, p. 63.

2. Ponsky JL, Gauderer MWL, Stellato TA (1985) Percutaneous approaches to enteral alimentation. Am J Surg 149(1): 102-105.

3. Blomberg J, Lagergren J, Martin L, Mattsson F, Lagergren P (2012) Complications after percutaneous endoscopic gastrostomy in a prospective study. Scand J Gastroenterol 47(6): 737-742.

4. Hucl T, Spicak J (2016) Complications of percutaneous endoscopic gastrostomy. Best Pract Res Clin Gastroenterol 30(5): 769-781.

5. Kim HS, Bang CS, Kim YS, Kwon OK, Park MS, et al. (2014) Two Cases of Gastrocolocutaneous Fistula with a Long Asymptomatic Period after Percutaneous Endoscopic Gastrostomy. Intest Res 12(3): 251-255.

6. Pitsinis V, Roberts P (2003) Gastrocolic fistula as a complication of percutaneous endoscopic gastrostomy. Eur J Clin Nutr 57(7): 876-878.

7. Tokunaga T, Kubo T, Ryan S, Tomizawa M, Yoshida S, et al. (2008) Long-term outcome after placement of a percutaneous endoscopic gastrostomy tube. Geriatr Gerontol Int 8(1): 19-23.

8. Rimon E, Kagansky N, Levy S (2005) Percutaneous endoscopic gastrostomy; evidence of different prognosis in various patient subgroups. Age Ageing 34(4): 353-357.
9. Huang SY, Levine US, Raper SE (2005) Gastrocolic fistula with migration of feding tube into transverse colon as a complication of percutaneous endoscopic gastrostomy. AJR Am J Roentgenol 184(3): S65-S66.

10. Smyth GP, McGreal GT, McDermott W (2003) Delayed presentation of a gastric colocutaneous fistula after percutaneous endoscopic gastrostomy. Nutrition 19(10): 905-906.

11. Friedmann R, Feldman H, Sonnenblick M (2007) Misplacement of percutaneously inserted gastrostomy tube into the colon: report of 6 cases and review of the literature. JPEN J Parenter Enteral Nutr 31(6): 469-476.

12. Tominaga K, Saigusa Y, Ito S, Hirahata K, Nemoto Y, et al. (2007) Percutaneous endoscopic gastrostomy with the aid of a colonoscope to avoid gastrocolic fistula formation. Endoscopy 39 suppl 1: E112-E113.

13. Croaker GDH, Najmaldin AS (1997) Laparoscopically assisted percutaneous endoscopic gastrostomy. Pediatric Surg Int 12(2-3): 130131.

14. Yamazaki T, Sakai Y, Hatakeyama K, Hoshiyama Y (1999) Colocutaneous fistula after percutaneous endoscopic gastrostomy in a remnant stomach. Surg Endosc 13(3): 280-282.

15. Lenzen H, Weismuller T, Bredt M, Bahr M (2012) Education and imaging. Gastrointestinal: PEG feeding tube migration into the colon; a late manifestation. J Gastroenterol Hepatic 27: 1254.

16. Stefan MM, Holcomb GW, Ross AJ (1989) Cologastric fistula as a complication of percutaneous endoscopic gastrostomy. JPEN J Parenter Enteral Nutr 13(5): 554-556.

17. Lee HJ, Choung RS, Park MS (2014) Two cases of uncommon complication during percutaneous endoscopic gastrostomy tube replacement and treatment. Korean J Gastroenterol 63(2): 120-124.

18. Hwang JH, Kim HW, Kang DH, Choi CW, Park SB, et al. (2012) A Case of endoscopic treatment for gastrocolocutaneous fistula as a complication of percutaneous endoscopic gastrostomy. Clin Endosc 45(1): 95-98.

19. Bertolini R, Meyenberger C, Sulz MC (2014) First report of colonoscopic closure of a gastrocolocutaneous PEG migration with over-thescopeclipsystem. World J Gastroenterol 20(32): 11439-11442.

20. Lee J, Kim J, Kim Hİ, Oh CR, Choi S, et al. (2018) Gastrocolocutaneous fistula: An unusual case of gastrostomy tube malfunction with diarrhea. Clin Endosc 51(2):196-200.
Creative Commons Attribution 4.0 International License

For possible submissions Click Here

\section{Submit Article}

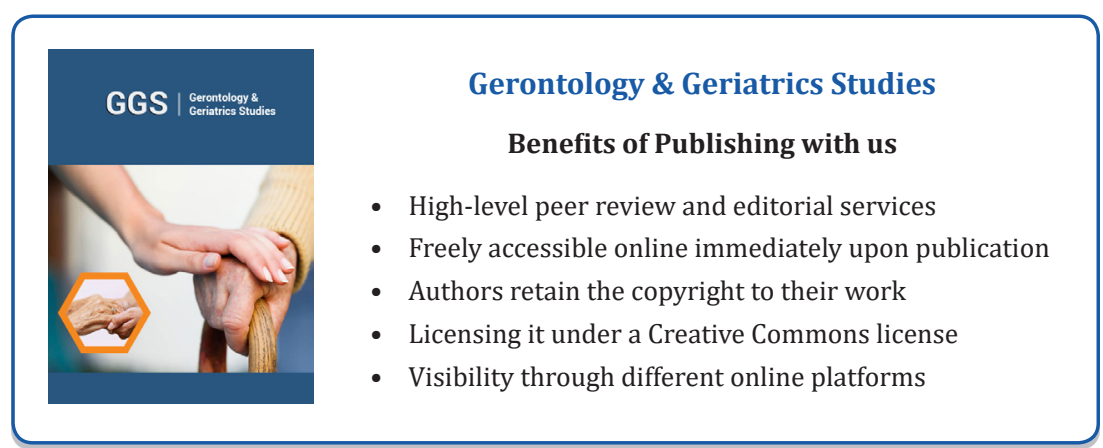

